\title{
Histopathological study of Plutella xylostella infected by three entomopathogenic fungal species
}

\author{
Jinming Xia, Zheng Huang, Qiongbo $\mathrm{Hu}^{*}$ \\ College of Natural Resources and Environment, South China Agricultural University, Guangzhou, China; \\ *Corresponding Author: hqbscau@126.com
}

Received 4 June 2013; revised 9 July 2013; accepted 18 July 2013

Copyright (C) 2013 Jinming Xia et al. This is an open access article distributed under the Creative Commons Attribution License, which permits unrestricted use, distribution, and reproduction in any medium, provided the original work is properly cited.

\begin{abstract}
The diamond back moth, Plutella xylostella (L.), is a major pest of the cruciferous vegetables around the world. Mycoinsecticide is a choice to alternate the high toxic chemical insecticides to control this pest. However, the application of mycoinsecticides was limited for their slower and instable control effects. In order to comprehend the different infection rates of different fungal strains against insect hosts, the strains SB005 of Beauveria bassiana, SM016 of Metarhizium anisopliae and SP020 of Isaria fumosorosea, which respectively had the $\mathrm{LT}_{90} \mathrm{~S}(1.0 \times$ $10^{7}$ sporces $/ \mathrm{mL}$ ) 4.5, 6.3 and $6.1 \mathrm{~d}$, were selected to compare their histopathological feature in infecting the larvae of Plutella xylostella. The results indicated that SM016 and SP020 strains were similar in symptons and infection process. Differently, the strain SB005 had more disease spots on body and could penetrate the cuticle of headcapsule. These probably are the reasons for Beauveria bassiana SB005 strain more quickly kill diamond moth.
\end{abstract}

Keywords: Infection; Beauveria; Metarhizium; Isaria; Diamond Moth

\section{INTRODUCTION}

The diamond back moth, Plutella xylostella (L.), is a major pest of the cruciferous vegetables around the world, especially in Southeast Asia and is extremely destructive if no chemical control measures are taken. As a result, more than a billion US Dollars were invested in insecticide control measures against diamondback moth in the early 1990's [1]. However, massive spraying chemical insecticides not only harms natural enemies and weak control effect of natural ecological system, but also re- sults in the resistance to the chemical pesticides. The diamond back moth is well-known for its ability to rapidly develop resistance to almost all chemical classes of insecticide in areas with intensive use of crop protection products [2,3]. Also, the resistance was found in Bacillus thuringiensis delta-endotoxins used in open field applications and expressed in genetically modified crop plants [4]. Although, diamides are the latest chemical class of insecticide to be introduced for global control of $P$. xylostella and have been shown to be highly efficacious in many agricultural settings. However, in 2011 the first complaints of reduced efficacy were reported by Chinese farmers in the Guangdong province and these anecdotal reports were subsequently confirmed by studies showing high levels of resistance in some populations of $P$. xylostella [5].

The application of a new type of biological pesticides against $P$. xylostella has become an inevitable trend [6]. Alternatively, microbial insecticides [7,8], and insectparasitic nematodes [9] are used as environmentally friendly biological control methods.

Mycoinsecicides have been playing an extremely important role in the biological control of pests. They have advantages of rich diversity of species, wide range of geographical distribution and insect host diversities. Over 170 products have been developed based on at least 12 species of fungi. Some species of the genera Beuaveria, Metarhizium, Isaria and Nomuraea have virulence to diamondback moth. However, the disadvantage of slowly killing pests limits the use of mycoinsecticides in smallscale [10]. In previous experiments, the authors found that different fungal species and strains have various killing rates (Xia et al., no publish). Our researches showed that the Beauveria bassiana strain SB005 had more quickly killing diamondback moth larvae than that Metarhizium anisopliae strain SM016 and Isaria fumosorosea strain SP020 had. Their $\mathrm{LT}_{90}$ values at the dosage of $1 \times 10^{7}$ conidiospores $/ \mathrm{mL}$ were $4.5 \mathrm{~d}, 6.3 \mathrm{~d}$ and 6.1 
d, respectively. In order to reveal the reasons of different killing rates of the three strains, in this study we would like to investigate the histopathological processes of $P$. xylostella infected by the fungi strains and apply a wider understanding to mycoinsecticides for colleagues.

\section{MATERIALS AND METHODS}

\subsection{Fungal Strains and Culture}

Beauveria bassiana, Metarhizium anisopliae and Isaria fumosorosea strains SB005, SM016 and SP020 were isolated from soil and insect hosts by the authors. When gave the concentration of $1 \times 10^{7}$ conidiospores $/ \mathrm{mL}$, their $\mathrm{LT}_{90}$ values to diamond moth were determined as $4.5 \mathrm{~d}$, $6.3 \mathrm{~d}$ and $6.1 \mathrm{~d}$, respectively. To get conidiospores, these strains were inoculated from slants to PDA plates and cultured for 14 days at $26^{\circ} \mathrm{C}$. Then, the conidiospores were scraped from the plates. The conidiospores were suspended with $0.05 \%$ Tween 80 solution. The suspensions concentrations were determined by means of haemacytometer and regulated to $1 \times 10^{7}$ conidiospores $/ \mathrm{mL}$ for using.

\subsection{Insects and Rearing}

The population of $P$. xylostella was reproduced more than 10 generations in lab. They were reared on the plant of cabbage, Brassica oleracea, in an air-conditioned greenhouse at $25^{\circ} \mathrm{C} \pm 1{ }^{\circ} \mathrm{C}$ and the photoperiod of L: D 16 $\mathrm{h}: 8 \mathrm{~h}$. The third instars larvae were selected to use.

\subsection{Inoculation}

The immersion method [11] was used for inoculation. The individuals of diamondback moth's third instars larvae were dipped into the conidiospores suspension $(1 \times$ $10^{7}$ conidiospores $/ \mathrm{mL}$ ) or $0.05 \%$ Tween 80 solution (CK) for $10 \mathrm{~s}$. There were 20 larvae treated in each fungal strain. After dryness, each pest was removed to a $20-\mathrm{cm}$ diameter Petri dish placed a piece of wet filter paper $(20 \mathrm{~cm}$ diameters) at the bottom. Then, the dishes were transferred in a climatic cabinate (Zhujiang LRH-250-Gb, Shaoguan Hongtai Medical Instrument Ltd. Guangdong, China) at $25^{\circ} \mathrm{C} \pm 1{ }^{\circ} \mathrm{C}$ and $>95 \%$ R.H. Every 12 h, 2 - 3 larvae were picked out for paraffin sections. Also, the pictures were taken on time when the outer symptoms were found on the pests.

\subsection{Paraffin Sections}

The larvae were fixed with Carnoy's fluid for 24 hours, then, washed 2 times with $70 \%$ alcohol (w/w). The fixed samples were embedded in paraffin wax and cut into sections of $5-6 \mu \mathrm{m}$. The sections were stained with Mayer's hematoxylin and 1\% eosin Y solution according to the procedure described by Sano [12] (1965). The samples were examined and taken pictures with microscope system (Leica-DM 4000B, Leica Microsystems Ltd. North Point, Hong Kong, China).

\section{RESULTS AND DISCUSSION}

\subsection{Symptoms}

On the earlier periods, a few melanized little points were firstly found on larvae cuticles of $P$. xylostella larvae about $30 \mathrm{~h}$ after treatment with the three fungi species (strains). Then, after treatments $40 \mathrm{~h}$, more, larger and blacker spots were recorded (Figure 1). Inoculated by strain SB005, lots of small, irregular and numerous spots were found in the insects mainly at the abdominal segment and legs (Figures $1 B 1$ and B2). Furthermore, the caudal legs turned black more than abdominal segments. On the contrary, a few of large and roughly spherical spots were found in strain SM016 treatments (Figures 1C1 and C2). As to strain SP020 treatments, many larger, irregular shaped spots appeared on the thoracic section back, abdominal segment and the legs (Figures 1A1 and A2).

On the late periods, the symptoms of the larvae were different when treated by different fungi strains. After 72 $\mathrm{h}$ treated with the strain SP020, the body shrank and deformed to a shape as "C" with light green and yellowish color and occasionally moved when touched (Figure 2A). At the $56 \mathrm{~h}$ treated by the strain SB005, the larvae were closed to die, the inactive and red-like bodies were covered by a few white hyphae (Figure 2B). However, the different symptoms were found in the larvae treated with the strain SM016, its bodies were spasticity at the midterm of the infection and then shrank deformation to the shape of "C" with green thoracic feet and abdomen and yellowish back (Figure 2C).

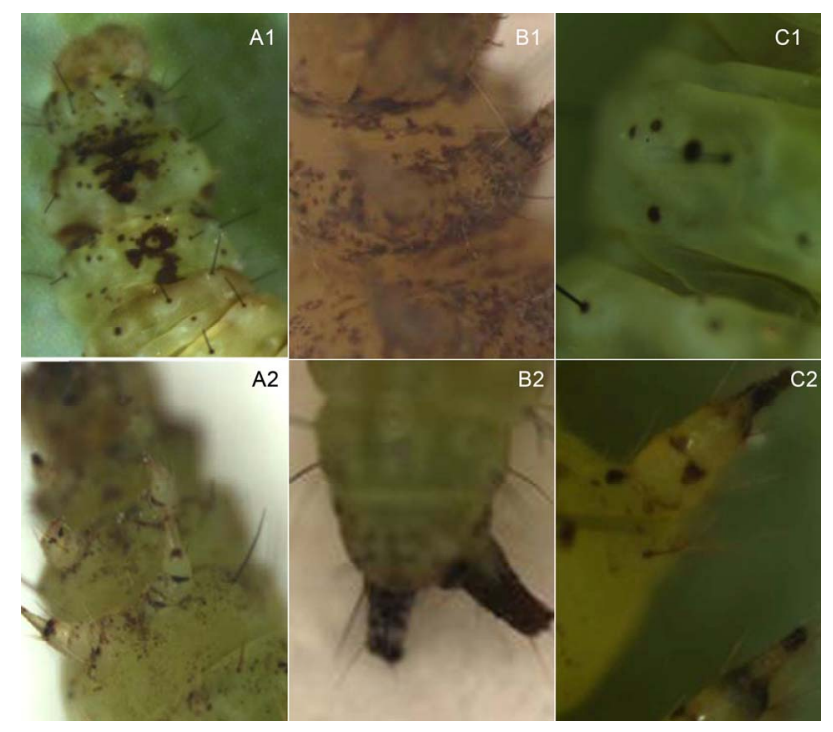

Figure 1. External symptoms of diseased Plutella xylostella after $40 \mathrm{~h}$ treated with the three fungal strains. A1/2, SP020 treatments; B1/2, SB005 treatments; C1/2, SM016 treatments. 


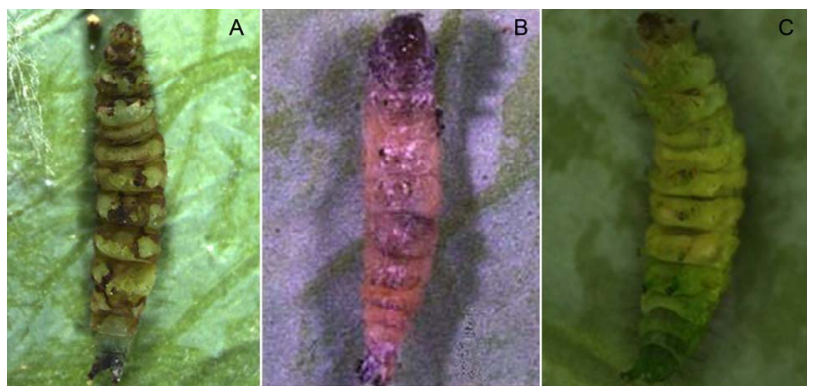

Figure 2. The dying symptoms of Plutella xylostella treated by SP020 after $72 \mathrm{~h}$ (A), treated by SB005 after $56 \mathrm{~h}$ (B) and treated by SM016 after $70 \mathrm{~h}(\mathrm{C})$.

\subsection{Invading Pathway}

In order to check the changes in treatments, the health moths were sectioned firstly. The pictures of paraffin sections showed that tissues and cuticles were clear and no hyphae were found (Figure 3).

From the Paraffin sections, hyphae were found in cuticles of body and appendage (specially, legs and mouthpart) within $24 \mathrm{~h}$ treated with the three fungi strains (Figures 4-7). Totally, there were more mycelia in cuticles of strain SP020 and SM016 treatments (Figures 4-6). However, only the SB005 treatment was found hyphae in cuticle of head capsule (Figure 7).

\subsection{Infection Process}

Totally, it took less than $72 \mathrm{~h}$ from the insect inculated with fungi strains to death. The Beauveria strain SB005 had the fastest infection process for about $56 \mathrm{~h}$, while the strains need more than $70 \mathrm{~h}$. However, there were similar histopathological changes in the infection processes in the three strains (Figures 8-10). SB005 was taken as an example (Figure 8) to address the infection process. After $12 \mathrm{~h}$ treated, conidia attaching to the epidermis began to germinate and penetrate into the cuticle (Figure 8A). After $24 \mathrm{~h}$, laminated structure of cuticle around the hyphae became hardened and the hyphae reproduced in the cuticle (Figures 8B and C). After $36 \mathrm{~h}$, hyphae were seen to break cells of the epidermis and were surrounded by many Blood lymphocytes (Figure 8D). After 48 h, hyphae in the haemocoel reproduced rapidly with the fat body disintegrated beginning (Figure 8E). Meanwhile, a few hyphae invaded into the muscle and other tissues. At $56 \mathrm{~h}$, fat body was almost disintegrated, cuticle was degraded and hyphal layer appeared (Figure 8G). Mycelia overgrew in the insect body (Figure 8H). Haemocoel and legs were almost captured by hyphae and detachment of the midgut cells was observed. Contents in the silkgland disappeared and digestive tract tissues began to disintegrated, compared to various tissues and organs of the healthy body (Figures 8I-K).

In the dying periods, there were some different changes in three strains treatments. In SB005 treatment, hyphae were just found around the visceral muscle. Perivisceral fat body, Malpighian tubes and muscle were not influenced,

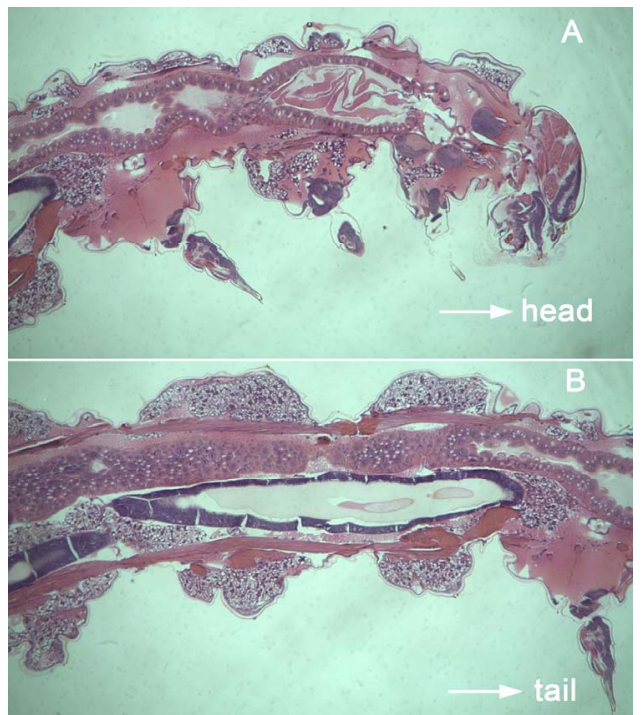

Figure 3. Paraffin sections profiles of health diamond moth (CK).

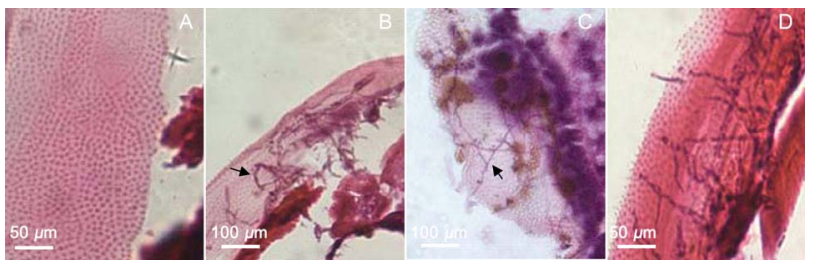

Figure 4. Hyphae in cuticle after treatment $24 \mathrm{~h}$. A: Healthy (CK); B: treated by strain SP020; C: treated by strain SB005; D: treated by strain SM016.

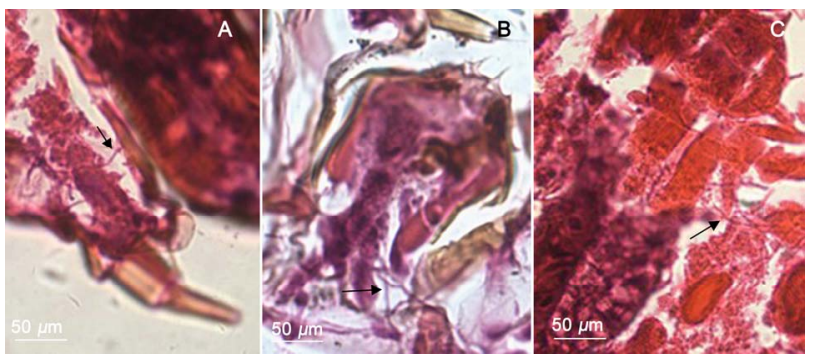

Figure 5. Hyphae in mouthparts after treatment $24 \mathrm{~h}$. A: treated by SP020; B: treated by SB005; C: treated by SM016.

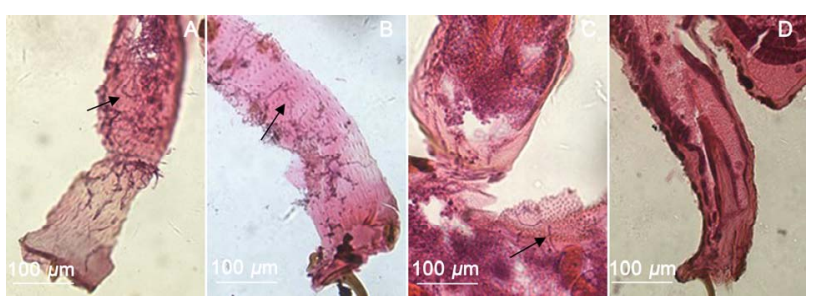

Figure 6. Hyphae in legs after treatment $24 \mathrm{~h}$. A: treated by SP020; B: treated by SB005; C: treated by SM016; D: health (CK). 


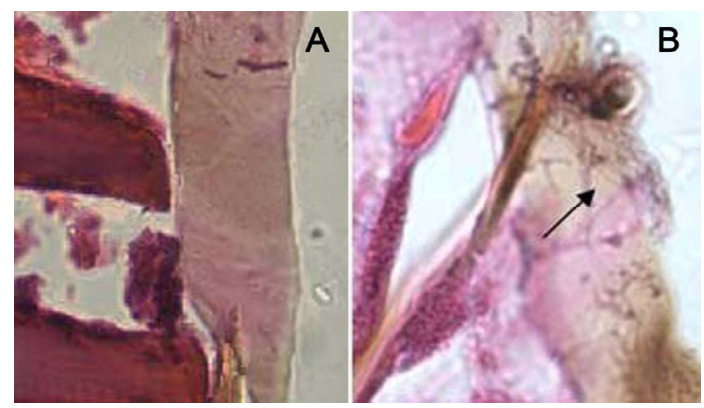

Figure 7. Hyphae in head cuticle after SB005 strain treatment $24 \mathrm{~h}$. A: health $(\mathrm{CK})$; B: treatment.

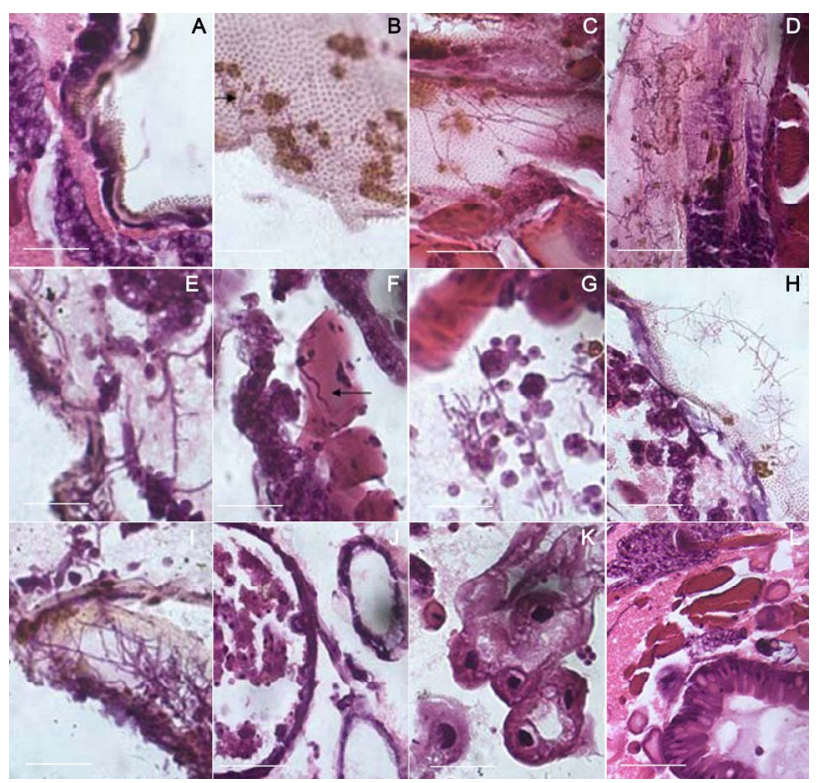

Figure 8. The process of Beauveria bassiana SB005 strain infecting Plutella xylostella larvae. A: germinating and penetrating to cuticle at $12 \mathrm{~h}$ post-inoculation; B: melanism spots on cuticle at $24 \mathrm{~h}$; C: hyphae expanding in the cuticle at $24 \mathrm{~h}$; D: hyphal bodies on epidermis at $36 \mathrm{~h}$; E: hyphal bodies infecting fat bodies and muscle tissues at $48 \mathrm{~h}$; F: hyphae in hemocoel at $56 \mathrm{~h}$; G: fat bodies disintegrated at $56 \mathrm{~h} ; \mathrm{H}$ : a hyphal layer on the surface of the larvae at $56 \mathrm{~h}$; I: muscle tissues in the legs disintegrated at $56 \mathrm{~h}$; J: the hemocoel of dying insect at $56 \mathrm{~h}$; K: malpighian tubes pathologically changed at $56 \mathrm{~h}$; L: healthy tissues and organs of the insect (CK). Bar $=50 \mu \mathrm{m}$.

but the peripheral fat bodies were nearly disintegrated and the midgut was almost integrated but the peritrophic membrane got separated from gut cells (Figure 11A). However, in the strain SP020 treatment (Figure 11B), hyphae grew vigorously in the body, organs were almost destroyed, fat bodies were completely decomposed, Malpighian tubes were damaged with a monolayer cell membrane left and the intestinal wall cells were damaged with decomposition and shedding. Similar with SP020, after $72 \mathrm{~h}$ treated with SM016 strain, the haemocoel was filled with the hyphae and a few hyphae bodies invaded into the gut, tissues like the Malpighian tubes and muscle

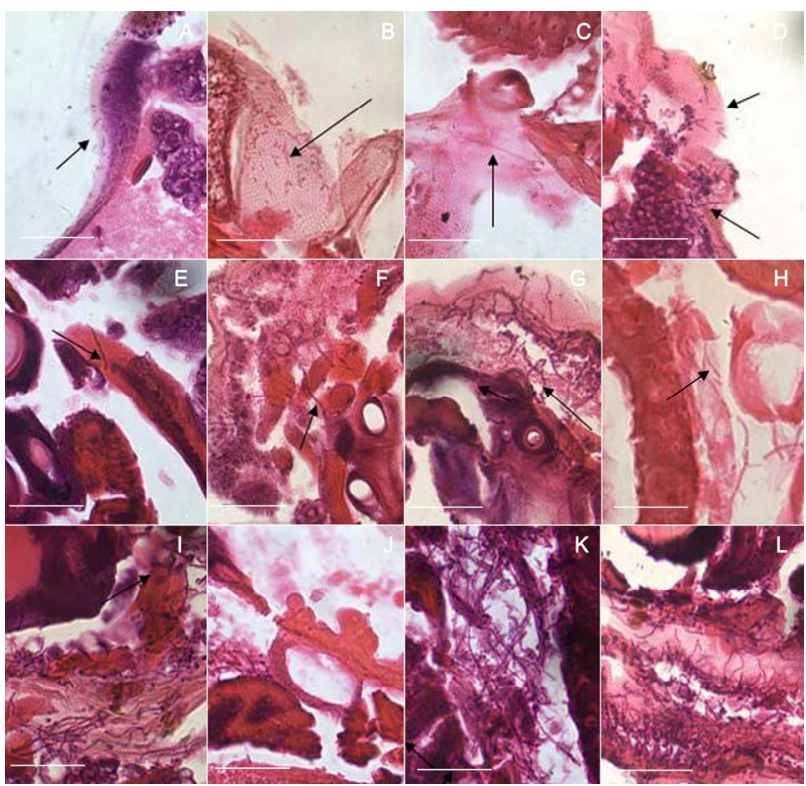

Figure 9. The process of Metarhizium anisopliae strain SM016 infecting Plutella xylostella larvae. A: germinating and penetrating to cuticle at $12 \mathrm{~h}$ post-inoculation; B-C: hyphae in cuticle at $24 \mathrm{~h}$; D: hyphal bodies at $30 \mathrm{~h}$; E: fatbody at $36 \mathrm{~h}$; F: muscles at $36 \mathrm{~h}$; G: fat bodies disintegrated at $54 \mathrm{~h}$; H: midgut at $60 \mathrm{~h}$; I: brain at $60 \mathrm{~h}$; J: midgut at $60 \mathrm{~h}$; K: hyphae in hemoceol at $70 \mathrm{~h}$; L: hyphae at $70 \mathrm{~h}$. Bar $=50 \mu \mathrm{m}$.

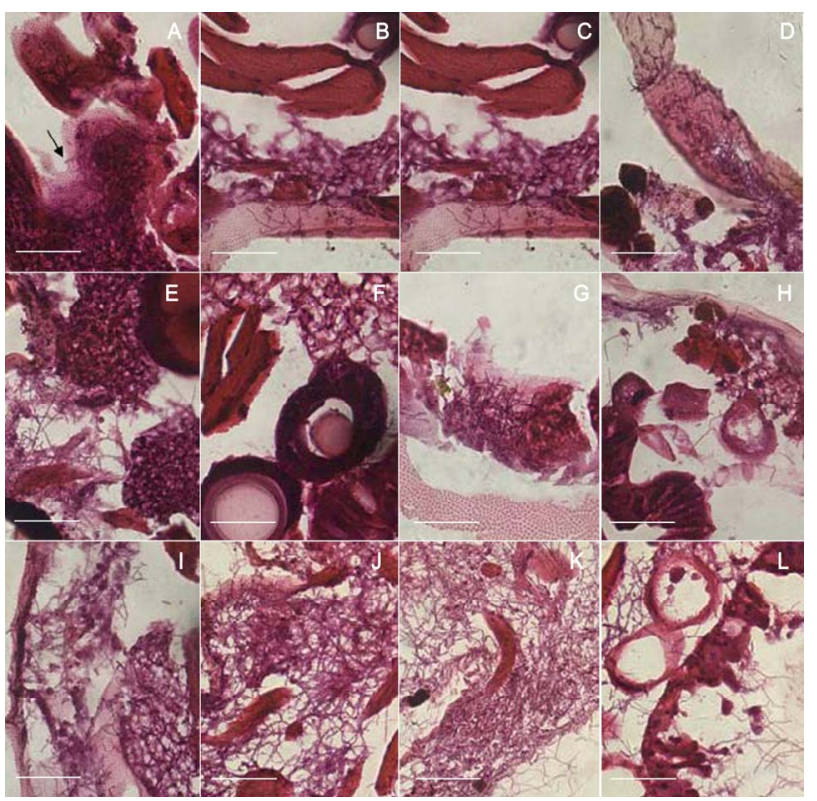

Figure 10. The process of Isaria fumosorosea SP020 strain infecting Plutella xylostella larvae. A: germinating and penetrating to cuticle at $12 \mathrm{~h}$ post-inoculation; B: hyphae in cuticle at $18 \mathrm{~h}$; C: hyphae expanding in the cuticle at $24 \mathrm{~h}$; D: hyphae in feed at $36 \mathrm{~h}$; E: fatbody at $48 \mathrm{~h}$; F: silk gland at $48 \mathrm{~h}$; G: hyphae in tissues at $56 \mathrm{~h}$; H: hyphae in hemoceol at $56 \mathrm{~h}$; I: cuticle and fatbody at $60 \mathrm{~h}$; J: hyphae in hemoceol at $72 \mathrm{~h}$; K: hyphae in feed at $72 \mathrm{~h}$; L: silk gland and midgut. Bar $=50 \mu \mathrm{m}$.

were also invaded by hyphae (Figure 11C). 


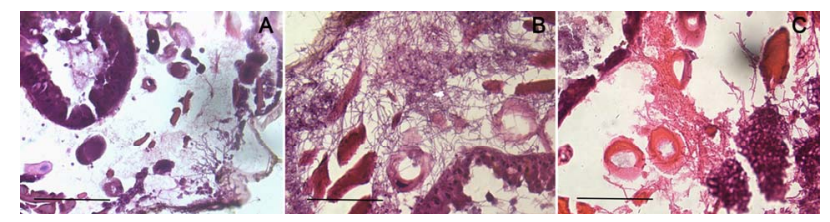

Figure 11. Dying state of diamondback moth larvae infected by three strains. A: $56 \mathrm{~h}$ postinoculation of SB005 strain; B: $72 \mathrm{~h}$ postinoculation of SP012 strain; C: $70 \mathrm{~h}$ postinoculation of SM016 strain. Bar $=100 \mu \mathrm{m}$.

\subsection{Discussion}

The entire process of entomogenous fungi infecting insects included conidia attachment, germination and appressoria formation, penetrating cuticle and invading hemoceol, damaging inner organisms and tissues, to the end producing new generation conidia. The speed to kill insects is clearly related to the infection process.

In this experiment, we observed that diamond moth treated with Beauveria bassiana SB005 strain had more small brown melanisms spots over their body surface. It indicates that the strain has more penetrating points which is benefit to defeat the host immunity. So, it seems that more penetrating points may be an important reason for fungi being more quickly in killing host insects.

Meanwhile, SB005 strain could invade head capsule of diamondback moth. It means that it may soon damage brain tissues resulting in the destruction of the nervous system. It is maybe another reason for Beauveria bassiana with faster effectiveness against the moth.

However, we also found that SB005 strain had less hyphae in moth dying states. It implies that moth probably died before its nutrition is exhausted by SB005 strain mycelia. It is maybe related to earlier death of brain, mycotoxins secreted and killed hosts or other more complicated reasons.

After all, a preliminary conclusion could be given, more invading points and penetrating head cuticle probably are the reasons for Beauveria bassiana SB005 strain being more quickly in killing diamond moth.

\section{ACKNOWLEDGEMENTS}

This research was supported by National High Technology Research and Development Program (“863” Program) of China (2012AA101505).

\section{REFERENCES}

[1] Talekar, N.S. and Shelton, A.M. (1993) Biology, ecology and management of the diamondback moth. Annual Review of Entomology, 38, 275-301. http://dx.doi.org/10.1146/annurev.en.38.010193.001423

[2] Zhao, J.Z., Collins, H.L., Li, Y.X., Mau, R.F.L., Thompson G.D., Hertlein, M., Andaloro, J.T., Boykin, R. and
Shelton, A.M. (2006) Monitoring of diamondback moth (Lepidoptera: Plutellidae) resistance to spinosad, Indoxacarb, and emamectin benzoate. Journal of Economic Entomology, 99, 176-181.

http://dx.doi.org/10.1603/0022-0493(2006)099[0176:MO DMLP]2.0.CO;2

[3] Sparks, T.C., Dripps, J.E., Watson, G.B. and Paroonagian, D. (2012) Resistance and cross-resistance to spinosynsA review and analysis. Pesticide Biochemistry and Physiology, 102, 1-10. http://dx.doi.org/10.1016/j.pestbp.2011.11.004

[4] Tabashnik, B.E., Carriere, Y., Dennehy, T.J., Morin, S., Sisterson, M.S., Roush, R.T., Shelton, A.M. and Zhao, J.Z. (2003) Insect resistance to transgenic Bt crops: Lessons from the laboratory and field. Journal of Economic Entomology, 96, 1031-1038.

http://dx.doi.org/10.1603/0022-0493-96.4.1031

[5] Wang, X. and Wu, Y. (2012) High levels of resistance to chlorantraniliprole evolved in field populations of Plutella xylostella. Journal of Economic Entomology, 105, 1019-1023. http://dx.doi.org/10.1603/EC12059

[6] Grzywacz, D., Rossbach, A., Rauf, A., Russell, D.A., Srinivasan, R. and Shelton, A.M. (2010) Current control methods for diamondback moth and other brassica insect pests and the prospects for miproved management with lepidopteran-resistant $\mathrm{Bt}$ vegetable brassicas in Asia and Africa. Crop Protection, 29, 68-79. http://dx.doi.org/10.1016/j.cropro.2009.08.009

[7] Batta, Y.A., Rahman, M. and Powis, K. (2011) Formulation and application of the entomopathogenic fungus: Zoophthora radicans (Brefeld) Batko (Zygomycetes: Entomophthorales). Journal of Applied Microbiology, 110, 831-839. http://dx.doi.org/10.1111/j.1365-2672.2011.04939.x

[8] Ali, S., Huang, Z. and Ren, S. (2010) Production of cuticle degrading enzymes by Isaria fumosorosea and their evaluation as a biocontrol agent against diamondback moth. Journal of Pest Science, 83, 361-370. http://dx.doi.org/10.1007/s10340-010-0305-6

[9] Park, H.W., Kim, H.H., Youn, S.H., Shin, T.S., Bilgrami, A.L., Cho, M.R. and Shin, C.S. (2012) Biological control potentials of insect-parasitic nematode Rhabditis blumi (Nematoda: Rhabditida) for major cruciferous vegetable insect pests. Applied Entomology and Zoology, 47, 389397. http://dx.doi.org/10.1007/s13355-012-0131-9

[10] Faria, M.R. and Wraight, S.P. (2007) Mycoinsecticides and mycoacaricides: A comprehensive list with worldwide coverage and international classification of formulation types. Biological Control, 43, 237-256. http://dx.doi.org/10.1016/j.biocontrol.2007.08.001

[11] Hussain, A., Tian, M.Y. and He, Y.R. (2010) In vitro and in vivo culturing impacts on the virulence characteristics of serially passed entomopathogenic fungi. Journal of Food Agriculture \& Environment, 8, 481-487.

[12] Sano, Y. (1965) Histological techniques. Nanzando Company, Tokyo. 